1. (Bachelors Hons. Emergency \& Intensive Care, MSPH) Lecturer/Research Officer, Department of Public Health, Armed Forces Post Graduate Medical Institute, Rawalpindi.

2. (BS Hons. Bio Sciences, MSPH) Lecturer/Research Officer, Department of Public Health, Armed Forces Post Graduate Medical Institute, Rawalpindi

3. (Bachelors Hons. Emergency \& Intensive Care, MSPH) Lecturer/Research Officer, Department of Public Health, Armed Forces Post Graduate Medical Institute, Rawalpindi

4. (MBBS, MCPS Family Medicine FCPS Community Medicine) Associate Professor, Department of Public Health, Armed Forces Post Graduate Medical Institute, Rawalpindi

5. (MBBS, MPH)

Assistant Professor,

Department of Public Health, Armed Forces Post Graduate Medical Institute, Rawalpindi

6. (Bachelors Hons. MSPH) Ch. Pervaiz Ellahi Institute of Cardiology Multan.

Correspondence Address:

Farman Ali

Address. Room No. 417

Qasim Hall Boys Hostel

Nishtar Hospital Multan

Email. farmiali@hotmail.com

Article received on:

22/08/2017

Accepted for publication: $15 / 03 / 2018$

Received after proof reading: 00/00/2018

\section{FOLIC ACID INTAKE;}

ROLE OF HEALTHCARE PROVIDERS IN COUNSELING AND PERCEPTIONS OFWOMEN ABOUT IMPORTANCE OF FOLIC ACID INTAKE IN CHILDBEARING AGE

Aamira Hashmi', Qandeel Tahir ${ }^{2}$, Muhammad Imran ${ }^{3}$, Naila Azam ${ }^{4}$, Rukhsana Roshan ${ }^{5}$, Farman Ali ${ }^{6}$

ABSTRACT... Objectives: Study objectives were devised to assess perceptions of women regarding importance of folic acid intake, to evaluate role of healthcare providers in counseling of women for folic acid intake, to find out association between perceptions of women with folic acid intake practices and with counseling of healthcare providers. Study Design: A cross sectional survey. Setting: Gynecology and Obstetrics Wards and OPDs of Tertiary Care and Teaching Hospitals of District Rawalpindi. Period: July-December 2016. Methodology: Study participants were approached by using convenient sampling technique and sample size was of 271 women of reproductive age. attending gynecology and obstetrics wards and OPDs of tertiary care and teaching hospitals of district Rawalpindi. After obtaining consent from institutional review board, an interview-based questionnaire was used as data collection tool. Results: Out of 271 women of childbearing age, $60 \%$ perceived the importance of folic acid intake in diet. The highest counseling contribution was from doctors $(57.6 \%)$ while evaluation of role of healthcare providers was done regarding counseling. Those who had perceived importance of folic acid had a significant better intake $(p=0.03)$. There was a significant association between role of healthcare providers and perceptions $(p=0.02)$. Conclusion: Majority of women perceived importance of folic acid intake and doctors were playing a significant role in counseling of women regarding folic acid intake during pregnancy. Folic acid intake practices were significantly influenced by women's own perceptions and role of healthcare providers was a very important factor to direct perceptions of women.

Key words: $\quad$ Folic Acid Intake, Perceptions of Women, Role of Healthcare Providers.

Article Citation: Hashmi A, Tahir Q, Imran M, Azam N, Roshan R, Ali F. Folic acid intake; role of healthcare providers in counseling and perceptions of women about importance of folic acid intake in childbearing age. Professional Med $\mathrm{J}$ 2018; 25(7):1102-1107. DOI:10.29309/TPMJ/18.4268

\section{INTRODUCTION}

Daily requirement of 400 micrograms of folic acid is recommended for good health and prevention from neural tube and congenital defects. Women of childbearing age, whether they are teenagers or adults, must know the importance of folic acid intake and their perceptions play a vital role in this practice. Role of healthcare providers is also of prime importance in making women aware of the health benefits related to folic acid intake.

Sensitization and knowledge levels were intensively studied in women of childbearing age in order to explain the low prevalence of folic acid intake with variable results in different countries. Low folic acid intake, different interventions on folic acid intake increase women's awareness from $60 \%$ to $72 \%$ and knowledge from $21 \%$ to $45 \%$. At the same time, the folic acid intake increased only from $14 \%$ to $23 \%$, showing a positive but suboptimal effect. ${ }^{1}$ Changes in knowledge and awareness alone cannot be assumed to result in behavioral changes. ${ }^{2}$

Nevertheless, educational campaigns can be effective. A US study found that women aged 18 to 45 were attending a 15-minute computer-aided education session. The proportion of women who understood that folate can prevent birth defects rose from $26 \%$ in advance to $92 \%$ after the campaign. In general, the knowledge of women about the role of folic acid in the prevention of birth 
defects and on food and supplementary sources of folic acid improved according to campaigns, but women were less likely to understand the importance of taking folic acid before conception. ${ }^{3}$

Educational campaigns with different modes of communication were used to improve folic acid intake before and during pregnancy, but its effects appear to be variable. ${ }^{4-6}$ While many women of reproductive age worldwide may be aware of the potential benefits of folic acid during pregnancy ${ }^{7}$, compliance with the recommendations remains low. . $^{8-11}$ In the United States, the CDC and the March of Dimes have organized campaigns to educate both the public and health experts about the need for daily consumption of folic acid supplements by all women of childbearing age while healthcare professionals can play important role in advising women on folic acid ${ }^{12}$, they often fail to do so., ${ }^{713}$

Another strategy is public health campaigns, which point to behavioral changes in all individuals, not just the searcher. ${ }^{14}$ Official health education initiatives have fostered folic acid supplementation and a rich diet with folic acid..$^{15}$ Campaigns range from media communications and information to products and products discount coupons to enable improved labeling and in-store displays to promote food sources for folic acid.

Health education and promotion strategies may play important role for the improvement of folic acid intake and perceptions of childbearing women. To reduce the burden of congenital diseases those are linked with folic acid through awareness campaigns and counseling by the healthcare professionals. All this can be done easily by the healthcare working to the patients attending at OPDs and wards in the department of gynecology and obstetrics.

\section{OBJECTIVES}

Study objectives were devised to assess perceptions of women regarding importance of folic acid intake, to evaluate role of healthcare providers in counseling of women for folic acid intake, to find out association between perceptions of women with folic acid intake practices and with counseling of healthcare providers.

\section{METHODOLOGY}

A cross sectional survey was conducted from July-December 2016. Study participants were approached by using consecutive sampling technique. Gynae, Family and Emergency OPD were fixed as study settings and sample size of 271 women of reproductive age residing in Rawalpindi district were approached. Pilot study was conducted and questionnaire modification was done to cater for more clear and pertinent response leading to achievement of designed objectives. Study objectives were devised to assess perceptions of women regarding importance of folic acid intake, to evaluate role of healthcare providers in counseling of women for folic acid intake, to find out association between perceptions of women with folic acid intake practices and with counseling of healthcare providers as well. After obtaining consent from institutional review board and respondents, data collection was started using an interview-based questionnaire. SPSS version 21 was used for data analysis. Analysis was of two main parts that are descriptive and inferential analysis. In descriptive part, results were in the form of frequency and percentage and in inferential part, association was checked among dependent and independent variables.

\section{RESULTS}

A total of 271 women in child bearing age were included in the study. Of the 271 respondents, the highest percentage (58.3\%) of women was in age category 24-32 years. Majority of the respondents $(56.1 \%)$ in the study had education above matriculation level. Seventy one percent of respondents (193/271) were not having any previous medical condition. Fifty nine percent (159/271) of respondents had heard about folic acid intake. Detailed information on Sociodemographic profile and information about folic acid intake is shown below in Table-I. 


\begin{tabular}{|c|c|}
\hline \multicolumn{2}{|c|}{ Socio-Demographic Profile } \\
\hline Variables & Frequency (\%) \\
\hline $\begin{array}{l}\text { Age } \\
15-23 \text { yrs } \\
24-32 \text { yrs } \\
33-41 \text { yrs } \\
>41 \text { yrs }\end{array}$ & $\begin{array}{c}19(7 \%) \\
158(58.3 \%) \\
66(24.4 \%) \\
28(10.3 \%)\end{array}$ \\
\hline $\begin{array}{l}\text { No of Children } \\
\text { No child } \\
1-3 \\
4-6 \\
>7\end{array}$ & $\begin{array}{c}66(22.1 \%) \\
165(60.9 \%) \\
43(15.9 \%) \\
3(1.1 \%)\end{array}$ \\
\hline $\begin{array}{l}\text { No of Pregnancies } \\
\text { No pregnancy } \\
1-3 \\
4-6 \\
>7\end{array}$ & $\begin{array}{c}54(19.9 \%) \\
161(59.4 \%) \\
42(15.5 \%) \\
14(5.2 \%)\end{array}$ \\
\hline $\begin{array}{l}\text { Frequent mode of Delivery } \\
\text { None } \\
\text { Normal delivery } \\
\text { C-section }\end{array}$ & $\begin{array}{c}62(22.9) \\
133(49.1) \\
75(27.7 \%)\end{array}$ \\
\hline $\begin{array}{l}\text { Occupation } \\
\text { Employed } \\
\text { Unemployed }\end{array}$ & $\begin{array}{l}108(39.9 \%) \\
163(60.1 \%)\end{array}$ \\
\hline $\begin{array}{l}\text { Residence } \\
\text { Rawalpindi/Islamabad } \\
\text { Other }\end{array}$ & $\begin{array}{c}179(66.1 \%) \\
92(33.9 \%)\end{array}$ \\
\hline $\begin{array}{l}\text { House hold expenditure } \\
<20,000 \\
20,000-40,000 \\
>40,000\end{array}$ & $\begin{array}{c}100(36.9 \%) \\
84(31 \%) \\
87(32.1 \%)\end{array}$ \\
\hline \multicolumn{2}{|c|}{ Background Information About Folic Acid Intake } \\
\hline $\begin{array}{l}\text { Knowledge about Folic acid intake } \\
\text { Yes } \\
\text { No }\end{array}$ & $\begin{array}{l}159(58.7 \%) \\
112(41.3 \%)\end{array}$ \\
\hline $\begin{array}{l}\text { Source of Information } \\
\text { Doctor } \\
\text { Nurse } \\
\text { Doctor/nurse } \\
\text { CHW/CMW/Others }\end{array}$ & $\begin{array}{c}156(57.6 \%) \\
52(19.2 \%) \\
16(5.9 \%) \\
47(17.3 \%)\end{array}$ \\
\hline $\begin{array}{l}\text { Counseling for Folic acid intake } \\
\text { Yes } \\
\text { No }\end{array}$ & $\begin{array}{c}186(68.6 \%) \\
85(31.4 \%)\end{array}$ \\
\hline $\begin{array}{l}\text { Take Folic acid only in Pregnancy } \\
\text { Yes } \\
\text { No }\end{array}$ & $\begin{array}{c}208(76.8 \%) \\
63(23.2 \%)\end{array}$ \\
\hline $\begin{array}{l}\text { Take Folic acid rich food } \\
\text { Yes } \\
\text { No }\end{array}$ & $\begin{array}{l}150(55.4 \%) \\
121(44.6 \%)\end{array}$ \\
\hline
\end{tabular}

\section{Perceptions of Women About Folic Acid Intake} Seventy nine percent (215/271) of the respondents reported that folic acid is beneficial for mother and child. Seventy one percent (192/271) respondents agreed to the statement that folic acid should be taken in the first trimester only. Eighty percent (218/271) respondents knew that folic acid tablets are yellow colored and sixty eight percent (185/271) respondents agreed folic acid should also be taken prior to pregnancy. Seventy one percent (192/271) respondents were aware about the fact that green leafy vegetables are rich source of folic acid. Seventy six percent respondents agreed to the statement that over cooking vegetables reduces their nutritional value. Majority of respondents agreed that folic acid deficiency during pregnancy causes abnormalities in new born babies. Detailed results of perception of women are listed below in TableII.

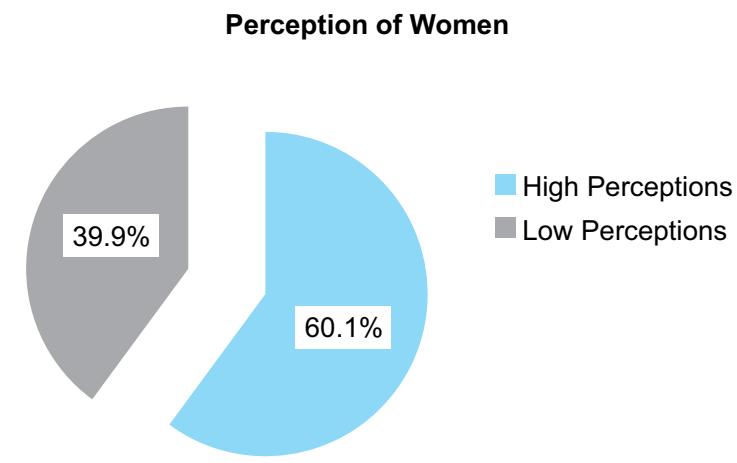

Figure-1. Perception of women regarding folic acid intake

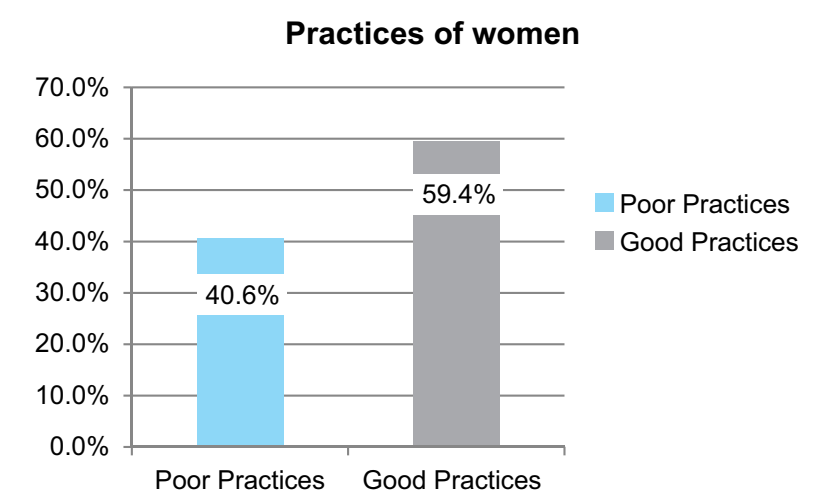

Figure-2. Practices regarding folic acid intake

A chi-square test was carried out to find the association of counseling provided by healthcare providers and folic acid intake practice. TableIII below shows that respondents who received counseling from doctors perceived a higher need for intake of folic acid during child bearing age than respondents who received counseling 
from other sources. There was a significant association between role of healthcare providers and perception of women $(p=0.02)$. Similarly, respondents who perceived importance of folic acid intake had a significant better folic acid intake $(p=0.03)$, details given in Table-III.

\begin{tabular}{|c|l|c|c|c|}
\hline \multicolumn{2}{|c|}{ Variables } & \multicolumn{2}{c|}{ Response } \\
\cline { 3 - 4 } & \multicolumn{2}{|c|}{ Agree } & Neutral & \multicolumn{1}{c|}{ Disagree } \\
\hline 1 & Folic acid intake beneficial for mother and child & $215(79.3 \%)$ & $42(15.5 \%)$ & $30(11.1 \%)$ \\
\hline 2 & Intake important during $1^{\text {st }}$ trimester & $192(70.8 \%)$ & $49(18.1 \%)$ & $6(2.2 \%)$ \\
\hline 3 & Yellow colored tablets & $218(80.4 \%)$ & $47(17.3 \%)$ & $14(5.2 \%)$ \\
\hline 4 & Taken prior to pregnancy & $185(68.3 \%)$ & $72(26.6 \%)$ & $18(6.6 \%)$ \\
\hline 5 & Green leafy vegetables a rich source & $192(70.8 \%)$ & $61(22.5 \%)$ & $21(7.7 \%)$ \\
\hline 6 & Excessive cooking reduces nutritional value & $205(75.6 \%)$ & $45(16.6 \%)$ & $32(11.8 \%)$ \\
\hline 7 & Deficiency (abnormalities) & $198(73.1 \%)$ & $41(15.1 \%)$ & $44(16.2 \%)$ \\
\hline 8 & Taken on specific time & $142(52.4 \%)$ & $85(31.4 \%)$ & $109(40.2 \%)$ \\
\hline 9 & Not required, present in food & $93(34.3 \%)$ & $69(25.5 \%)$ & \\
\hline
\end{tabular}

Table-II. Perception of women regarding folic acid intake

\begin{tabular}{|c|c|c|c|c|}
\hline \multirow{2}{*}{\multicolumn{2}{|c|}{ Independent Variables }} & \multicolumn{2}{|c|}{ Perception of Women } & \multirow{2}{*}{ Chi-Square Results } \\
\hline & & High Perceptions & Low Perceptions & \\
\hline 1 & Folic acid Intake (Yes) & $118(56.7 \%)$ & $90(43.3 \%)$ & $\chi 2=4.35, d f=1, p=0.037$ \\
\hline \multirow{3}{*}{2} & Counseling by Doctors & $82(52.6 \%)$ & $74(47.7 \%)$ & \multirow{3}{*}{$\chi^{2}=9.83, \mathrm{df}=2, \mathrm{p}=0.007$} \\
\hline & Counseling by Nurses & $34(65.4 \%)$ & $18(34.6 \%)$ & \\
\hline & Counseling by LHWs, CMWs and others & $47(74.6 \%)$ & $16(25.4 \%)$ & \\
\hline
\end{tabular}

Table-III. Association between perception of women; folic acid intake and counseling practices

\section{DISCUSSION}

This cross sectional study highlights the importance of folic acid intake, counseling practices and perception of women regarding folic acid intake during child bearing age. Knowledge and practices regarding the importance and intake of folic acid was reported good by majority of the respondents.

Knowledge regarding the importance of folic acid was reported good by 159 (58.7\%) of respondents. Results of this study matched with a study done in Rawalpindi where 172 (43\%) of respondents showed awareness regarding the need for folic acid in pregnancy. ${ }^{16}$ In the present study, improvement was seen in the knowledge of participants regarding importance of folic acid intake; the possible reason behind this could be the improvement in counseling practices.

Highlighting the importance of folic acid during child bearing age, majority of the respondents $(73.1 \%)$ in present study agreed to the fact that deficiency of folic acid causes abnormalities in new born babies, on the contrary previous studies done in same settings showed that 161 (40.25\%) of respondents thought folic acid deficiency in pregnancy results in newborn abnormalities while only $34.5 \%$ of respondents from the previous study showed interest in going to awareness campaigns. ${ }^{16}$ The uninterested participants therefore showed a negative attitude while our study highlighted the importance of awareness campaigns and counseling practices and a significant association is observed between perceptions of women and counseling received by respondents. In the present study, respondents who had received counseling from doctors' perceived higher need for intake of folic acid during child bearing age as compared to respondent who had been counseled by nurses or other staff $(p=0.02)$.

In the present study practices regarding folic acid intake were reported good by $59.4 \%$ of respondents. A study done in similar setting showing poor practices of respondents (43\%) regarding intake of folic acid rich foods, on other hand $51.25 \%$ had received folic acid supplementation during pregnancy. ${ }^{16}$ In the 
present study, 55.4\% respondents reported that they were taking folic acid rich foods, $76.8 \%$ respondents reported that they were taking folic acid supplementation during pregnancy, this significant improvement in the practices of women shows that counseling done by doctors is playing a significant role in improving the folic acid intake. The previous study done by Aliya in 2014 highlighted the importance of continuous education and motivation towards this basic micronutrient intake. Folic acid intake is important before conception and during first trimester to avoid congenital defects in newborns. Studies show that pre-conceptional supplementation of folic acid prevents considerable fraction of neural tube defects ${ }^{17,18}$ and this message needs to be communicated to women.

In the present study it was reported that $57.6 \%$ of the respondents received counseling regarding folic acid intake from doctors, $19.2 \%$ respondents received counseling and advice from nurses and $17.3 \%$ respondents received counseling from CHW, LHW and CMW. Studies have shown that community pharmacist can also help in providing counseling and can play a vital public health role. In a study done by Rodrigues; Ninety five percent of pharmacists reported that folic acid prevents certain birth defects. Twenty nine percent pharmacists reported that they "always" or "mostly" discuss importance of multivitamins with customers. ${ }^{19}$

Studies have also shown that higher literacy levels lead to greater improvements in lifestyles. People who are educated are more aware and knowledgeable than people who have a lower literacy level. A study done by Aliya in Rawalpindi emphasized that the fact that increasing literacy levels along with awareness campaigns, media education, counseling done by healthcare professionals plays a vital role in highlighting the importance of preventive measures. ${ }^{16}$

\section{CONCLUSION}

Majority of women perceived importance of folic acid intake and doctors were playing a significant role in counseling of women regarding folic acid during pregnancy. Folic acid intake practices were significantly influenced by women's own perceptions and role of healthcare providers was a very important factor to direct perceptions of women.

\section{Acknowledgement}

The authors desire to deliver their gratitude to all study participants.

Copyright (C) 15 Mar, 2018.

\section{REFERENCES}

1. Chivu C, Tulchinsky T, Soares-Weiser K, Braunstein $\mathrm{R}$, Brezis M. A Systematic Review of Interventions to Increase Awareness, Knowledge, and Folic Acid Consumption Before and During Pregnancy. American Journal of Health Promotion. 2008; 22(4):237245.

2. Green, L.W., and Kreuter, M.W. (1991). Health promotion planning: An educational and environmental approach. Mountain View, CA: Mayfield Publishing Company.

3. Schwarz E, Sobota M, Gonzales R, Gerbert B. Computerized Counseling for Folate Knowledge and Use. American Journal of Preventive Medicine. 2008; 35(6):568-571.

4. Bailey L, Rampersaud G, Kauwell G. Folic acid supplements and fortification affect the risk for neural tube defects, vascular disease and cancer: evolving science. The Journal of Nutrition. 2003; 133(6):1961S-1968S.

5. Wald $\mathrm{N}$ Bower $\mathrm{C}$. Folic acid and the prevention of neural tube defects. BMJ. 2004; 310(6986):1019-1020.

6. Botto L. International retrospective cohort study of neural tube defects in relation to folic acid recommendations: are the recommendations working?. BMJ. 2005; 330(7491):571-0.

7. Gupta H Gupta P. Neural tube defects and folic acid. Indian Pediatrics. 2004; 41(6):577-86.

8. Braekke K, Staff AC. Periconceptional use of folic acid supplements in Oslo. Acta Obstet Gynecol Scand. 2003; 82:620-627.

9. Coll O, Pisa S, Palacio M, Quinto L, Cararach V. Awareness of the use of folic acid to prevent neural tube defects in a Mediterranean area. Eur J Obstet Gynecol Reprod Biol. 2003; 115:173-177.

10. Oleary M, Donnell RM, Johnson H. Folic acid and prevention of neural tube defects in 2000 improved awareness-low periconceptional uptake. Ir Med J. 


$$
2001 ; 94: 180-181 .
$$

11. Centers for Disease Control and Prevention (CDC), Knowledge about folic acid and use of multivitamins containing folic acid among reproductive aged women - Georgia, 1995. MMWR Morb Mortal Wkly Rep. 1996; 45:793-795.

12. Power ML, Holzman GB, Schulkin J. Knowledge and clinical practice regarding folic acid among obstetrician gynecologists. Obstet Gynecol. 2000; 95:895-898.

13. Marsack CR, Alsop CL, Kurinczuk JJ, Bower C. Prepregnancy counseling for the primary prevention of birth defects: rubella vaccination and folate intake. Med J Aust. 1995; 162:403-406.

14. Ogden J. Health Psychology: A Textbook, 3rd edn. Berkshire, England: Open University Press, 2007.

15. March of Dimes launches new Ad campaign to alert women about folic acid and birth defects. March Dimes 2000. http://www. marchofdimes.com/ aboutus/791_1893.asp.

16. Hisam A, Rahman M, Mashhadi SF. Knowledge, attitude and practice regarding folic acid deficiency; A hidden hunger. Pak J Med Sci 2014; 30(3):583-588. doi: http://dx.doi.org/10.12669/pjms.303.4716.

17. Muthayya S, Rah JH, Sugimoto JD, Roos FF, Kraemer $\mathrm{K}$, Black RE. The global hidden hunger indices and maps: an advocacy tool for action. PLoS One. 2013; 8(6). doi: 10.1371/journal.pone.0067860.

18. Fekete K, Berti C, Trovato M, Lohner S, Dullemeijer C, Souverein OW, et al. Effect of folate intake on health outcomes in pregnancy: a systematic review and meta analysis on birth weight, placental weight and length of gestation. Nutr J. 2012; 19(11):75. doi: 10.1186/1475-2891-11-75.

18. Rodrigues CR, Dipietro NA. Knowledge of folic acid and counseling practices among Ohio community pharmacists. Pharm Pract (Granada). 2012; 10(3):168172.

The greatest prison that people live in is the fear of what other people think.

\section{- David Icke -}

\section{AUTHORSHIP AND CONTRIBUTION DECLARATION}

\begin{tabular}{|c|l|l|}
\hline Sr. \# & \multicolumn{1}{|c|}{ Author-s Full Name } & \multicolumn{1}{|c|}{ Contribution to the paper } \\
\hline 1 & Aamira Hashmi & Concieve idea, Design study. \\
2 & Qandeel Tahir & Manuscript Writing. \\
3 & Muhammad Imran & Data Collection. \\
4 & Naila Azam & Data Analysis. \\
5 & Rukhsana Roshan & Manuscript Writing. \\
6 & Farman Ali & Proof Reading.
\end{tabular}

